\title{
MICROPROPAGATION OF CYMBIDIUM ALOIFOLIUM (L.) SW., A MEDICINAL ORCHID BY ARTIFICIAL SEEDS TECHNOLOGY
}

\author{
SHREETI PRADHAN ${ }^{1}$, BABU LAL TIRUWA ${ }^{1}$, BIJAY R. SUBEDEE ${ }^{2}$ AND BIJAYA PANT ${ }^{1} \bowtie$ \\ ${ }^{1}$ Central Department of Botany, Tribhuvan University, Kirtipur \\ ${ }^{2}$ Research Center for Applied Science and Technology, Tribhuvan University, Kirtipur \\ bijayapant@gmail.com
}

\section{ABSTRACT}

Artificial seed technology is a rapidly growing area of research in plant cell and tissue culture. Application of this technology opens an alternative route for mass scale production, efficient delivery of cloned plantlets and fulfils the increasing demand of local growers. An attempt was made to produce artificial seeds and their subsequent regeneration of a highly valuable medicinal orchid of Nepal i.e. Cymbidium aloifolium. Artificial seeds were obtained through encapsulation of protocorms in calcium alginate beads. Protocorms were encapsulated by using $3 \%$ sodium alginate and $0.2 \mathrm{M}$ calcium chloride solution. Murashige and Skoog (MS) medium (1962) was used as the basal medium for in vitro germination and seedling development of artificial seed. In Cymbidium aloifolium, 20-25 days old in vitro grown protocorms were used for production of artificial seeds. Artificial seeds were inoculated on two different culture conditions of MS medium i.e. MS solid \& MS liquid with four different treatments i.e. strength of 1.0, 1/2, $1 / 4$ and MS media supplemented with plant growth regulators viz. BAP $(0.5 \mathrm{mg} / \mathrm{l})$ and NAA $(0.5 \mathrm{mg} / \mathrm{l})$. Highest percentage of germination (100\%) and plantlet conversion was found on hormone free full strength (1.0 MS) of MS liquid medium after 13-14 weeks of culture. Plantlets regenerated from artificial seeds with well developed shoot and root systems were successfully acclimatized in potting mixture of cocopeat, litter and sphagnum moss in a ratio 2:1:1.

Keywords: Protocorms, MS media, artificial seed, encapsulation, orchid

\section{INTRODUCTION}

Orchids, one of the most fascinating creations of nature, are also one of the most widely distributed groups of flowering plants. Nepal harbors about $457 \mathrm{spp}$ of native orchids belonging to 102 genera, out of which 18 species are endemic to Nepal (Rajbhandari, 2014). Thirteen species of Cymbidium have been reported from Nepal. Cymbidium aloifolium (L.) Sw., an epiphytic orchid grows on trees trunk which has high medicinal value. The plant is reported to have emetic and purgative properties. Paste of its parts (pseudobulb and leaves) is used as tonic and used over fractured or dislocated bones (Hossain et al., 2009; Pant \& Raskoti, 2013). Plant can be found in an altitude ranging from $300 \mathrm{~m}$ to $2900 \mathrm{~m}$ (Rajbhandari \& Dahal, 2004). It blooms from April to June and flower persists for approximately 20 days. The flower is yellowish with central radial stripes. Pod of Cymbidium aloifolium (L.) Sw. is large and greenish remains hanging arising from a very small pseudobulb enveloped by leaf bases.

Plant tissue culture technique provides a new dimension for efficient conservation and commercialization of numbers of rare and useful orchid species (Vij et al., 2004). Orchid 
produces huge number of seeds which are very minute and non-endospermic which rarely germinate in nature, they require an appropriate mycorrhizal fungus association for successful seed germination (Gutiarrez-Miceli et al., 2008; Pradhan et al., 2013). The fungal association is believed to provide physiochemical stimulus required for growth initiation (Sharma and Tandon, 1990; Ovando et al., 2005). Orchid seeds can be germinated in vitro without fungal association. Seed culture will help in the production of quality planting materials in larger scale.

Production of artificial seeds provides a new vista in in vitro plant propagation technology because it offers many useful advantages on a commercial scale. Artificial seed technology not only produce the artificial seeds but also used for their conversion into plantlets under in vitro and in vivo conditions. This technology is thus useful for multiplying large number of rare, threatened and endangered plant species which are difficult to regenerate through conventional methods and natural seeds.

The present study was aimed to standardize the protocol for propagation of Cymbidium aloifolium through artificial seed technology.

\section{MATERIALS AND METHODS}

\section{Source of explants}

Immature capsules of Cymbidium aloifolium were harvested from nature. Capsules were first washed under running tap water for at least 30 minutes to remove the soil or other particle attached to it. Then, capsules were surface sterilized under laminar air flow cabinet by using $70 \%$ alcohol for 2 minutes followed by $1 \%$ sodium hypochlorite solution for 15 minutes and were subsequently rinsed in sterile water for at least three times. After sterilization, capsules were dried on Whatsman filter paper and dissected longitudinally with the help of sterilized surgical blade to expose the powdery seeds. Seeds were scooped out and spread thinly over the surface of MS basal medium under aseptic condition. Protocorms were started to develop after 10 weeks of culture of seeds and $20-25$ days old protocorms were selected as primary explants for present study.

\section{Culture medium}

In vitro germination and subsequent development of artificial seed was carried out on two different conditions of MS (Murashige and Skoog, 1962) medium i.e. solid and liquid. Each media consists of different strength i.e. full (1.0), half (1/2) and quarter (1/4) and media supplemented with different concentration of plant growth regulators viz. $0.5 \mathrm{mg} / \mathrm{l} \mathrm{BAP}$ and $0.5 \mathrm{mg} / \mathrm{l} \mathrm{NAA}$ (Table 1). MS medium was fortified with $3 \%$ sucrose as carbon source with and without solidified with agar. The $\mathrm{pH}$ of MS media was adjusted to 5.8 before autoclaving. About $16-20 \mathrm{ml}$ of media was dispensed into each culture tube $(150 \times 25 \mathrm{~mm}$, Borosil) and autoclaved at pressure 15 psi and temperature of $121^{\circ} \mathrm{C}$ for 20 minutes. All cultures were maintained at $25 \pm 2^{\circ} \mathrm{C}$ under 500 lux illuminance for 16/8 hrs. (light/dark) photoperiod using cool white light (Philips, India).

\section{Encapsulation and Inoculation}

Protocorms were used as crucial explants to produce artificial seeds. For encapsulation of protocorms, $3 \%$ sodium alginate was used with $0.2 \mathrm{M}$ calcium chloride for complexation. Individual protocorms were separated and mixed in $3 \%$ sodium alginate matrix. This solution 
was poured into drop by drop on calcium chloride solution by using wide mouth and left it for at least 30 minutes to harden the alginate beads. After that, the beads now called as artificial seeds or synthetic seeds, were washed with sterile water for three times and dried on blotting paper. Artificial seeds were then inoculated on different strength of MS solid and liquid medium i.e. full strength (1.0), half strength (1/2) and quarter strength (1/4) and full strength of medium supplemented with $0.5 \mathrm{mg} / \mathrm{BAP}$ and $0.5 \mathrm{mg} / \mathrm{l} \mathrm{NAA}$ for their germination and regeneration (table 1). The cultures were kept at $25 \pm 2^{\circ} \mathrm{C}$ under $16 / 8 \mathrm{hrs}$ photoperiod from cool-white-light in culture room.

\section{Hardening}

Plantlets regenerated from artificial seeds of Cymbidium aloifolium after attaining the height of $3-4 \mathrm{~cm}$ were used for hardening process. Plants with well developed shoots and roots were taken out from the culture vessels and washed thoroughly with running tap water to remove the traces of agar without causing harm to roots. These plants were treated with $0.1 \%$ fungicide (Bavistin) solution for 5 minutes and again washed with sterile water. After washing, they were blot dried and finally acclimatized in pot containing potting mixture of cocopeat, litter and sphagnum moss in a ratio $2: 1: 1$. The potted plants were watered once a day and fertilized at weekly intervals with a foliar spray of a mixture of nitrogen, phosphorous and potassium (20:10:10). The potted plants were covered with a perforated plastic bag to maintain the humidity and kept under greenhouse until the seedlings were established. They were observed regularly.

\section{STASTICAL ANALYSIS}

Each treatment consisted of at least 6 explants and each experiment was repeated twice. Statistical analysis was done using an analysis of variance (ANOVA) one way classification system. The data obtained were analyzed using application software-Microsoft excel. The significant difference between the MS medium and MS medium supplemented with different growth hormones were analysed at $\mathrm{P} \leq 0.05$ using SPSS version 16.0 (SPSS Inc. USA).

\section{RESULTS}

Cymbidium aloifolium (L.) Sw. is one of the most important orchid, used for medicinal as well as ornamental purposes. In present study, in vitro production, germination and propagation of artificial seed was carried out by using 20-25 days old protocorms. Zhang et al. (2011) reproted that protocorms were the best propagator for artificial seed production in Dendrobium candidium. The production of artificial seed was done with the help of sodium alginate (3\%) and calcium chloride ( $0.2 \mathrm{M})$. Finally, the rounded bead of artificial seeds of cymbidium aloifolium were formed (fig. 1, A).

In present study, it was found that artificial seed was started to germinate in vitro after 5-6 weeks of culture in all the condition of MS liquid medium (fig. 1, B, C) whereas it took 7 weeks of culture on MS solid medium. During germination, artificial seeds become swollen after absorbing the nutrients, which produced elongated, green shoots followed by root formation. First shoot primordia was initiated from 7 weeks of culture while first root primordia was started to develop from 9 weeks of culture on full strength of liquid MS medium. In present study, complete seedling with healthy shoot and root were developed on hormone free MS liquid medium after 14 weeks 
of culture (fig. D). On MS solid medium, first shoot and root primodia were initiated after 9 and 15 weeks of culture on hormone free full strength of MS medium rather than 1/2, 1/4 strength and hormone supplemented MS solid medium. Well developed plantlet with healthy shoot and root were also observed after 18 weeks of culture on hormone free full strength of MS solid medium in comparison to other concentrations of MS solid medium (fig. 1, E).

\section{DISCUSSION}

In present study, in vitro germination and propagation of artificial seed of Cymbidium aloifolium was carried out on two conditions of MS basal media i.e. MS solid and MS liquid medium supplemented with various concentrations of BAP and NAA. The MS basal medium was found to be the most appropriate condition for both solid and liquid condition than that of $1 / 2 \mathrm{MS}, 1 / 4$ MS and MS supplemented with hormone BAP \& NAA. The most appropriate condition for the germination and multiplication of the artificial seed was concluded on the basis of time taken for the germination, efficiency of germination and growth and development of seedlings.

Among different concentration of both MS liquid and MS solid medium, MS liquid medium alone was found to be the most effective condition for earlier germination and propagation of artificial seed of Cymbidium aloifolium which took 14 weeks of culture to develop healthy plantlets. In present study, $100 \%$ conversion of plantlet from artificial seed was found on different strength and homone concentration of both MS solid and liquid medium (graph 1\&2). The present finding was supported by Corrie \& Tandon (1993) who reported $100 \%$ conversion of encapsulated Plb's into plantlet under in vitro condition in Cymbidium giganteum. Similarly, Sarmah et al. (2010) produced Vanda coerulea synseeds by encapsulating PLBs regenerated from the leaf base with a $94.9 \%$ conversion frequency. Nagananda et al. (2011) encapsulated the PLBs of Flickingeria nodosa and achieved $95 \%$ conversion after 3 months' storage at $4^{\circ} \mathrm{C}$. Gantait et al. (2012) obtained 96.4\% conversion in alginate- encapsulated Aranda $\times$ Vanda PLBs with $3 \%$ sodium alginate and $75 \mathrm{mM}$ calcium chloride. The present findings were dissimilar to the reports obtained by other researcher. Datta et al. (1999) found that modified Knudson medium supplemented with BAP $(1 \mathrm{mg} / \mathrm{l})$ and NAA $(1 \mathrm{mg} / \mathrm{l})$ was the most effective condition for germination of artificial seed of Geodorum densiflorum (Lam.) Schltr.

\section{GRAPH 1. In-vitro germination and seedling development from artificial seeds of Cymbidium aloifolium (L.) Sw. in different strength and homone concentration of MS liquid medium.}

\section{MS Liquid}

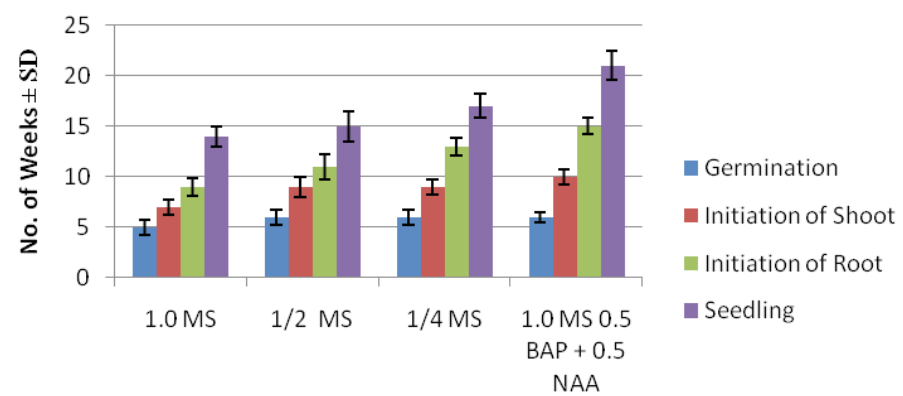


GRAPH 2. In-vitro germination and seedling development from artificial seeds of Cymbidium aloifolium (L.) Sw. in different strength and homone concentration of MS solid medium.

\section{MS Solid}

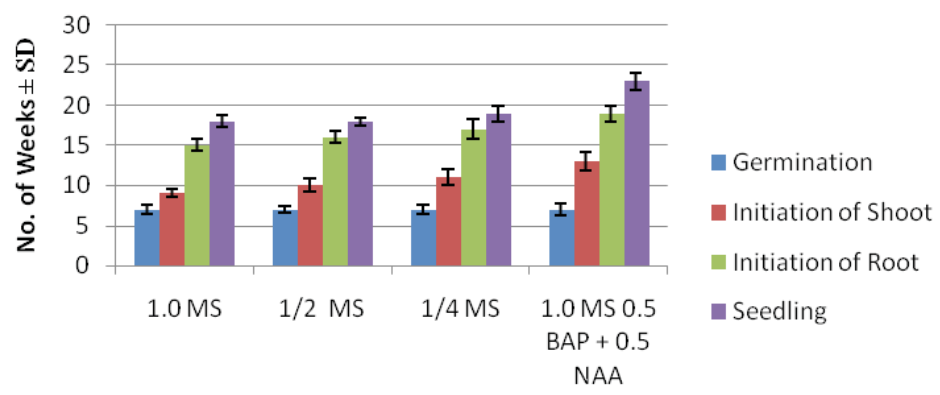

Media concentrations

Plantlets after attaining the height of 3-4 cm with well developed shoot and root were selected for hardening. These plantlets were acclimatized in earthen pots containing cocopeat, litter and sphagnum moss in 2:1:1 ratio and covered with perforated plastic bags to maintain require humidity (fig. E). About $80 \%$ plantlets were survived in this condition (fig. F)

In present study, it was concluded that full strength of MS liquid medium alone is the most effective condition for in vitro germination and propagation of artificial seed of Cymbidium aloifolium rather than other different strength and hormone supplemented MS liquid and MS solid medium. The present research might be useful to establish the protocol for alternative method of propagation of Cymbidium aloifolium by using artificial seed.

\section{ACKNOWLEDGEMENTS}

Authors are grateful to Central Department of Botany, Tribhuvan University, Kirtipur, Nepal for providing all laboratory facilities for this investigation. We highly acknowledge Nepal Academy of Science and Technology (NAST), Khumaltar, Lalitpur, Nepal the financial assistance to carry out the present research work. We extend our sincere gratitude to Prof. Dr. Sanu Devi Joshi, for her valuable suggestions.

\section{REFEERNCES}

CORRIE, S; TANDON, P (1993) Propagation of Cymbidium giganteum Wall, through high frequency conversion of encapsulated protocorms under in vivo and in vitro conditions. Indian J. Expt. Biol. 31: 61-64.

DATTA, K B; KANJILAL, B; DE SARKER, D (1999) Artificial seed technology: development of a protocol in Geodorum densiflorum (Lam) Schltr.-An endangered orchid. Current Science 76(8): 142-1145.

GUTIARREZ-MICELI, F A; T AYORA-TALAVERA, M; ABUD-ARCHILA, M; SALVADOR-FIGUEROA; L DENDOOVEN, L (2008) Acclimatization of micropropagated orchid Guarianthe harzianum. Asian J. Plant Sci. 7: 327-330.

GANTAIT, S; BUSTAM, S; SINNIAH, U R (2012) Alginate-encapsulation, short-term storage and plant regeneration from protocorm-like bodies of Aranda Wan Chark Kuan 'Blue'× Vanda coerulea Grifft. ex. 
Lindl.(Orchidaceae). Plant Growth Regulation 68(2): 303-311.

HOSSAIN, M M; SHARMA, M; PATHAK, P (2009) Cost effectivem protocol for in vitro mass propagation of Cymbidium aloifolium (L.) Sw., a medicinally important orchid. English Life Science. 9(6): 444-453.

MURASHIGE, T; SKOOG, F (1962) A revised medium for rapid growth and bio assay with tobacco tissue cultures. Physiol. Plant 15: 473-479.

NAGANANDA, G S; SATISHCHANDRA, N; RAJATH, S (2011) Regeneration of encapsulated protocorm like bodies of medicinally important vulnerable orchid Flickingeria nodosa (Dalz.) Seidenf. Int. J. Bot. 7: 310-313.

OVANDO, I; A DAMON, R; BELLO, D; AMBROSIO, V; ALBORES, LA; SALVADOR, M (2005) Isolation of endophytic fungi and then mycorrhizal potential for the tropical epiphytic orchids Cattleya skinneri, C. aurantiaca and Brassavola nodosa. Asian J. Plant Sci. 4: 309-315.

PANT, B; RASKOTI, B B (2013) Medicinal orchids of Nepal. Nepal: Himalayan Map House Pvt. Ltd.

PRADHAN, S; REGMI, T; PARMAR, G; PANT, B (2013) Effect of different media on in vitro seed germination and seedling development of Cymbidium aloifolium (L.) Sw. Nepal Journal of Sci. Technol. 14(1): 51-56.

RAJBHANDARY, K R; DAHAL, S (2004) Orchids of Nepal: a checklist. Botanica Orientalis 4: 89-106.

RAJBHANDARI, K R (2014) Orchids of Nepal: status, threat and conservation. In Proceedings of National Workshop on NTFP/ MAPs sector action plan development: Orchids. (Jha, P K (ed). Department of Plant Resources (DPR) and Central Department of Botany, Tribhuvan University, Kathmandu Nepal. pp.1-40.

SHARMA, S K; TANDON, P (1990) Asymbiotic germination and seedling growth of Cymbidium elegans Lindl. and Coelogyne punctulata lindl. as influenced by different carbon sources. J. Orchid Soc. Ind 4: 149-159.

SARMAH, D K; BORTHAKUR, M; BORUA, P K (2010) Artificial seed production from encapsulated PLBs regenerated from leaf base of Vanda coerulea Grifft. ex. Lindl.--an endangered orchid. Current Science (00113891). 98(5): 686-690.

VIJ, S P; AGGARWAL, S; PATHAK, P (2004) Regeneration competence of Cymbidium

Great Waltz $\times$ Valley flower roots: a study in vitro. J. Orchid Soc. India 18(1-2): 109-115.

ZHANG, Y; YAN, S; ZHANG, Y (2011) Factors affecting germination and propagators of artificial seeds of Dendrobium candidum. International Conference on Agricultural and Biosystems Engineering. Advances in Biomedical Engineering 1-2: 404-10. 

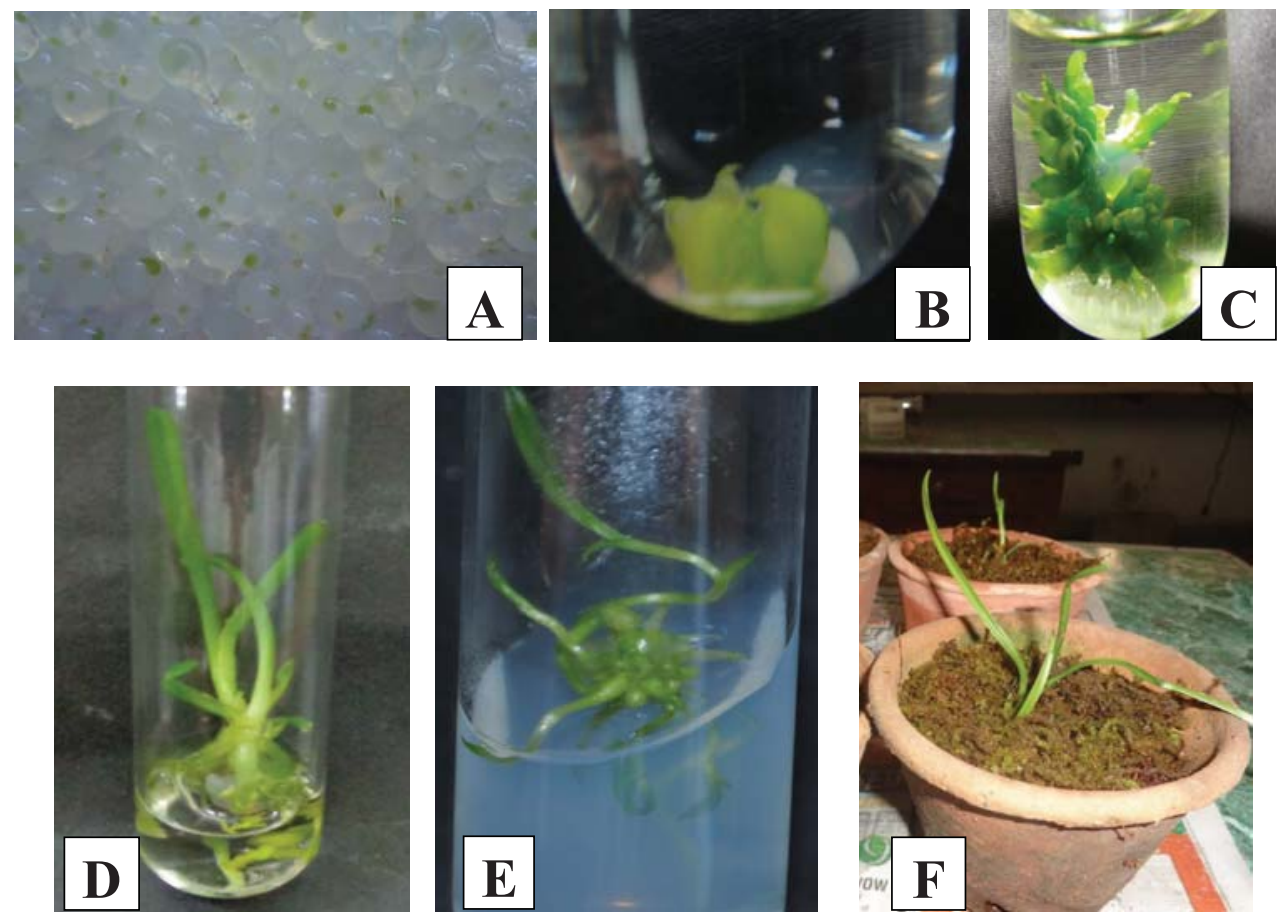

FIG.1. Production, germination and propagation of artificial seed containing protocorms of Cymbidium aloifolium. (A) $3 \%$ artificial seed (B) Germinated artificial seeds gave rise to shoot bud on $1 / 4$ MS liquid medium. (C) Multiple shoot buds on $1 / 2$ MS liquid medium. (D) Development of healthy roots and shoot buds on hormone free 1.0 MS liquid medium. (E) Multiplication of shoots with well developed roots on hormone free $1.0 \mathrm{MS}$ solid medium. (F) Hardening of in vitro plantlets on potting mixture of cocopeat, litter and sphagnum moss of 2:1:1 ratio. 